\title{
Histochemical Characterization of Early Response to Cochliobolus sativus Infection in Selected Barley Genotypes
}

\author{
Susana Rodríguez-Decuadro, Paula Silva, Oscar Bentancur, Fernanda Gamba, and Clara Pritsch
}

First, second, and fifth authors: Departamento de Biología Vegetal, third author: Departamento de Biometría y Estadística, and fourth author: Departamento de Protección Vegetal, Facultad de Agronomía, Universidad de la República, Garzón 780, Montevideo 12900, Uruguay. Accepted for publication 20 January 2014.

\section{ABSTRACT}

Rodríguez-Decuadro, S., Silva, P., Bentancur, O., Gamba, F., and Pritsch, C. 2014. Histochemical characterization of early response to Cochliobolus sativus infection in selected barley genotypes. Phytopathology 104:715-723.

Much effort is being made to breed barley with durable resistance to leaf spot blotch incited by Bipolaris sorokiniana (teleomorph: Cochliobolus sativus). We hypothesized that susceptibility and resistance traits in 11 diverse barley genotypes inoculated with a single $C$. sativus isolate might specify a range of distinct host cell responses. Quantitative descriptions of interaction microphenotypes exhibited by different barley genotype seedlings after infection with $C$. sativus are provided. Early oxidative re- sponses occurring in epidermis and mesophyll leaf tissue were monitored by histochemical analysis of $\mathrm{H}_{2} \mathrm{O}_{2}$ accumulation at 8,24 , and $48 \mathrm{~h}$ after inoculation. Cell wall apposition (CWA) in epidermal cells and hypersensitive reaction (HR) of epidermal or mesophyll tissue were early defenses in both resistant and susceptible genotypes. There were differences in level, duration, and frequency of occurrence for CWA and HR for the different barley genotypes. Occurrence of HR in epidermal cells at postpenetration stages was indicative of compatibility. Patterns of cell responses were microphenotypically diverse between different resistant and susceptible genotypes. This suggests that timing and level of response are key features of microphenotypic diversity that distinguish different functional mechanisms of resistance and susceptibility present in barley.
Cochliobolus sativus (Ito \& Kurib.) Drechs. ex Dastur (anamorph: Bipolaris sorokiniana (Sacc.) Shoem.) is a Dothideomycete that produces leaf spot blotch (SB) on economically important cereals such as wheat and barley. This pathogen is responsible for large production losses and has worldwide distribution with prevalence in warm, humid regions in Asia and the Americas $(23,32)$. Disease symptoms vary with level of resistance, in which the most resistant genotypes have small, round to oblong necrotic lesions and no chlorotic halo. Increase in hostpathogen compatibility results in larger oval necrotic lesions with well-defined chlorotic halos and a variable extent of diffuse chlorosis (8).

Defense against potential pathogens initiates by nonself and self-damaged or altered recognition mechanisms in the potential host. Nonself signals are conserved molecular motifs in structures specific for different microbes. Self signals are those derived from damaged or altered structural components of plant host (e.g., that can result from alteration of plant cell wall integrity). Microbes, including pathogens, also produce effectors that, upon entry into host cells, function to the advantage of the microbe's ability to colonize or occupy the host. These effectors are also recognized by the plant and can elicit a defense response. Early-detection surveillance mechanisms for diverse resistance types use similar or shared components of signal transduction networks. These resistance types include species-specific (nonhost) or race-specific resistances and quantitative basal resistance expressed in susceptible genotypes (17). Pathogen recognition is followed by cell wall apposition (CWA) accumulation and activation or production of antimicrobial compounds in the apoplast, including phyto-

Corresponding author: C. Pritsch; E-mail address: clara@ fagro.edu.uy

* The $\boldsymbol{e}$-Xtra logo stands for "electronic extra" and indicates that Figure 1 appears in color online.

http://dx.doi.org/10.1094/PHYTO-05-13-0133-R

(C) 2014 The American Phytopathological Society alexins, chitinases, proteases, and defensins (17). Accumulation of callose in CWA played an important defensive role in interactions involving Ustilago hordei and barley (a host) as well as nonhost wheat coleoptiles. The timing and extent of callose accumulation was correlated with effective resistance (11). Luna et al. (27) showed that callose deposition defense response in Arabidopsis is controlled by distinct signaling pathways that depend on either environmental conditions or recognition of pathogen-associated molecular patterns.

Oxidative stress responses, involving production of reactive oxygen species (ROS) such as hydrogen peroxide $\left(\mathrm{H}_{2} \mathrm{O}_{2}\right)$, are very early cellular responses that follow pathogen recognition (30). Rapid ROS production can readily be visualized by histochemical methods at sites of fungal attack $(22,36)$. Increased levels of $\mathrm{H}_{2} \mathrm{O}_{2}$ are associated with cell wall strengthening and the hypersensitive reaction (HR). $\mathrm{H}_{2} \mathrm{O}_{2}$ is highly diffusible and may play a role in transducing signals in defense gene activation in cells under attack as well as those at systemic sites $(37,40,42)$.

$\mathrm{HR}$ is a localized cell-death response to pathogen attack involving biochemical and structural changes in efforts to restrict pathogen spread (26). ROS accumulation is correlated with stopping biotrophic pathogens from further growth. In contrast, necrotrophic pathogens may use resulting dead host cells not only as portals for plant entry but also as a nutrient source for further invasive growth (17). Therefore, the role of HR as a resistance strategy varies depending on the pathosystem. Thus, HR may restrict a pathogen exhibiting an initial biotrophic phase but may augment disease if this is followed by a necrotrophic phase during infection.

C. sativus has been classified as an hemibiotrophic fungus. Fungal hyphae initially penetrate the cuticle and epidermal cell wall, then enter cell space without actually disrupting integrity of the cell membrane. The second stage is necrotrophic and is associated with toxin release and epidermal and mesophyll cell death $(22,23,32)$. According to Kumar et al. $(22,23), \mathrm{H}_{2} \mathrm{O}_{2}$ may play a dual role in the barley-C. sativus interaction. Initial $\mathrm{H}_{2} \mathrm{O}_{2}$ 
accumulation in epidermal cell walls under host control may restrict fungal access, whereas high $\mathrm{H}_{2} \mathrm{O}_{2}$ accumulation in mesophyll tissue during the second stage results in massive tissue collapse and fungal colonization. Moreover, oxidative reactions occurring in mesophyll tissue are likely to be caused by fungal toxins rather than a programmed cell death response (22). The role of $\mathrm{H}_{2} \mathrm{O}_{2}$ in toxin-induced cell death is supported by the finding that fungal culture filtrates containing toxins triggered $\mathrm{H}_{2} \mathrm{O}_{2}$ accumulation and necrosis in barley leaves (22). Schäfer et al. (36) classified preinfection defense responses exhibited by epidermal cells into two lines of defense occurring at prepenetration and post-penetration stages of fungal infection. This was done by comparing the spatial and temporal pattern of defense responses against $C$. sativus exhibited by moderately susceptible 'Haisa' barley with its derived albino mutant, the supersusceptible albostrians. Defense responses in prepenetrated epidermal cells included CWA formation, HR, or both, and were found associated with failures in fungal penetration. Post-penetration defense consisted of HR in epidermal cells that might prevent successful infection, involving invasion and collapse of mesophyll.

Breeding for disease resistance is an efficient and ecologically sound strategy for disease control. Numerous studies have identified a range of different barley accessions with variation in SB resistance in terms of resistance phenotype and types or degree of response $(2,5,9,33,35,36)$. There is also reported variation in responses by seedling and adult plants $(2,5,39)$. Host-specific virulence has been reported in $C$. sativus isolates on 'Bowman' and derivatives in North Dakota $(7,15)$. Based on differential virulence exhibited by isolates collected mostly in North Dakota on three lines, three pathotypes were identified (43). Additional studies in Canada involving a larger number of $C$. sativus isolates and 12 plant lines revealed that a gene-for-gene model may not be the principal system operating in barley-C. sativus pathosystems. In this study, varying levels of aggressiveness (virulence) were most prominent among isolates (12). In spite of exhaustive study, very little is known regarding the diversity in $C$. sativus resistance mechanisms in barley.

Different mechanisms for SB resistance and susceptibility appear to operate in barley. Global expression profiling of the $C$. sativus-barley interaction could provide insight on the cellular and molecular factors contributing to resistance. Thus far, such studies with $C$. sativus have been restricted to a single accession of Hordeum vulgare subsp. spontaneum having SB resistance (29). On the other hand, comprehensive sequencing of expressed sequence tags (ESTs) was used to provide a global picture of barley genes differentially expressed during HR of a susceptible genotype in response to $C$. sativus (4). Also, although a number of studies have addressed the relationship between oxidative stress response and disease resistance in the barley-C. sativus interaction $(22,36)$, very few barley genotypes have been analyzed. Even fewer studies comparing defense response patterns by host cells have been done. Comparison of the $C$. sativus preinfection defense response (36) by genetically unrelated wheat genotypes at the seedling stage revealed a higher frequency of CWA in resistant compared with susceptible genotypes. However, significant differences in HR responses by epidermal host cells were not found, either before or after penetration by the invading hyphae (20). These authors suggested that frequency of CWA at early stages and extent of fungal colonization within mesophyll tissue would be useful indicators for genotypes with SB defense potential and for describing new resistance traits in cereals.

The aim of this study was to investigate whether host cell responses to challenge by a monosporic isolate of $C$. sativus varied among 11 barley genotypes exhibiting varying levels of resistance and how these host responses related to pathogen development. Interaction microphenotypes resulting from spatiotemporal patterns of the oxidative response, expressed as $\mathrm{H}_{2} \mathrm{O}_{2}$ accumulation at epidermis and mesophyll leaf cells during the early stages of infection, were evaluated by histochemical methods. We also monitored the progress of fungal colonization.

\section{MATERIALS AND METHODS}

Host and pathogen. Eleven barley (H. vulgare L.) genotypes with varying origins and levels of SB resistance were used in this study. Five genotypes were from the United States ('Morex', 'NDB112', Bowman, 'ND17293', and 'ND5883'), two were from Europe ('Ingrid' and 'Perun'), two from the International Center of Agricultural Research in Dry Areas (ICARDA)/International Maize and Wheat Improvement Center (CIMMYT) barley breeding program ('21IBON\#69' and 'Calicuchima-sib'), one from the INIA Uruguay barley breeding program ('CLE253'), and one was a line of unidentified origin ('TR6'). SB resistance in NDB112 is well known (39). Sources and pedigrees of barley germplasm are shown in Table 1. Plants were grown in 10-cm-diameter pots containing six seedlings of the same genotype. Pots were placed randomly in a growth chamber at $23^{\circ} \mathrm{C}$ and $70 \%$ relative humidity (RH) with a 16-h photoperiod $\left(100 \mu \mathrm{E} \cdot \mathrm{m}^{-2} \cdot \mathrm{s}^{-1}\right)$. For each genotype, independent pots were used for macrophenotypic and microphenotpic evaluations.

C. sativus 04.1 .4 was isolated from an infected barley leaf of line U5293 in Colonia, Uruguay. It was grown on potato dextrose agar (PDA) medium (Difco Laboratories, Detroit) at $23^{\circ} \mathrm{C}$ with a 12-h photoperiod $\left(100 \mu \mathrm{E} \cdot \mathrm{m}^{-2} \cdot \mathrm{s}^{-1}\right)$.

Inoculation. Conidial suspensions of $C$. sativus were prepared by removing mycelia from 14-day-old cultures, suspending in $0.02 \%$ Tween 20, then filtering through two layers of muslin cloth. Macroscopic infection response was evaluated in 14-dayold seedlings (grown in pots as described above) inoculated by spraying suspensions of 5,000 spores $/ \mathrm{ml}$ ( $0.2 \mathrm{ml} /$ seedling), according to Fetch and Steffenson (8). Histochemical analyses were done using 7-day-old seedlings inoculated with a suspension of 50,000 spores $/ \mathrm{ml}$, according to Schäffer et al. (36). Additional pots with each genotype were sprayed with $0.02 \%$ Tween 20 as

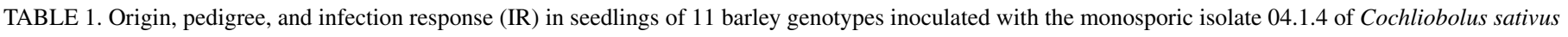

\begin{tabular}{|c|c|c|c|c|}
\hline Genotype & Spike type & Origin & Pedigree & Seedling IR ${ }^{y}$ \\
\hline ND5883 & Two-rowed & United States & Clipper//6916-105/Centennial & 9 \\
\hline Perun & Two-rowed & Europe & HE1728/Karat & 7 \\
\hline CLE 253 & Two-rowed & Uruguay & Perun/INIA Aromo & 7 \\
\hline Calicuchima-sib & Six-rowed & ICARDA-CIMMYT $^{\mathrm{z}}$ & LBIran/UNA8271//Gloria-sib/Comanche-sib & 7 \\
\hline 21IBON\#69 & Two-rowed & ICARDA-CIMMYT & Emir/3/Api/CM67//Bus/4/Shyri/5Sen & 6 \\
\hline Ingrid & Two-rowed & Europe & Balder//Binder/Opal & 5 \\
\hline Morex & Six-rowed & United States & Cree/Bonanza & 5 \\
\hline Bowman & Two-rowed & United States & Klages//Fergus/Nordic/3/ND1156/4/Hector & 4 \\
\hline TR6 & Six-rowed & Unidentified & Unidentified & 4 \\
\hline ND17293 & Two-rowed & United States & ND14651/ND15062 & 3 \\
\hline NDB112 & Six-rowed & United States & CI7117-17/Kindred & 3 \\
\hline
\end{tabular}

y IR values of 1 to 3, 4 to 5, and 6 to 9 are indicative of low, intermediate, and high compatibility, respectively (8).

z ICARDA-CIMMYT = International Center of Agricultural Research in Dry Areas/International Maize and Wheat Improvement Center. 
control. Following inoculation, each pot was first tightly covered and sealed with a nylon bag to maintain $>95 \% \mathrm{RH}$ and maintained in darkness for the $24 \mathrm{~h}$ after inoculation (hai). Pots were then returned to the growth chamber.

Evaluation of seedling infection responses at macroscopic level. Ten days after inoculation, infection response (IR) scores for each barley genotype were assessed on the second leaf of three randomly selected plants per pot using a scale of 1 to 9 (8). IR values of 1 to 3,4 to 5 , and 6 to 9 are indicative of low, intermediate, and high compatibility, respectively.

Microscopy of ROS-associated defense response and fungal development. Segments of the first leaf $(1 \mathrm{~cm}$ long) from three randomly selected plants per genotype per pot were sampled at 8 , 24, and 48 hai. In situ histochemical detection of $\mathrm{H}_{2} \mathrm{O}_{2}$ was done by staining with 3,3-diaminobenzadine (DAB) (D-8001; SigmaAldrich) following the protocol of Thordal-Christensen et al. (41), with modification. Briefly, leaf segments were infiltrated with $\mathrm{DAB}$ at $1 \mathrm{mg} / \mathrm{ml}(\mathrm{pH} \mathrm{3.8,} \mathrm{HCl})$ for $30 \mathrm{~min}$ and then incubated for $4 \mathrm{~h}$ in darkness. Subsequently, leaf samples were fixed and bleached in $0.15 \%$ trichloroacetic (wt/vol) in ethanol/chloroform $(4: 1, \mathrm{vol} / \mathrm{vol})$ for $48 \mathrm{~h}$, with one solution change at $24 \mathrm{~h}$. Fungal structures were observed in fixed-leaf segments by staining with $0.3 \%$ (wt/vol) Calcofluor (F-6259; Sigma-Aldrich) following the protocol of Rohringer et al. (34). Calcofluor-stained hyphae were observed using an epifluorescence microscope (Olympus Vanox AHBS3, excitation filter $368 \mathrm{~nm}$, barrier filter $420 \mathrm{~nm}$ ) while DAB-positive responses were observed by visible light microscopy. The appearance of 50 independent interaction sites was recorded for each of three samples per plant genotype (150 total), except for genotype NDB112, for which 450 interaction sites (nine plants) were evaluated. An interaction site was defined as a site where fungal structures were found in contact with a host cell showing localized accumulation of $\mathrm{H}_{2} \mathrm{O}_{2}$ (DAB ${ }^{+}$response). At each interaction site, presence or absence of $\mathrm{DAB}^{+} \mathrm{CWA}$ on epidermal cells was recorded. In addition, whole-cell DAB staining indicative of HR (18) was determined at either prepenetration (Pre-EHR) or post-penetration (Post-EHR) into epidermal tissues. Mesophyll cells exhibiting HR underneath either prepenetrated (Pre-MHR) or penetrated (Post-MHR) epidermal cells was also noted. Infection progress at interaction sites was documented as having hyphae present with appressorium, intracellular epidermal hyphae (IEH), and intercellular hyphae in mesophyll tissues (IMH). Percentage of penetrated epidermal cells expressing HR (\%EHRi) was also determined. In summary, three inoculation experiments were done with from three to six genotypes each and including genotype NDB112 as control. The three experiments included (in addition to NDB112) Perun, CLE253, 21IBON\#69, TR6, and Morex (experiment 1); Calicuchima-sib, Ingrid, and ND17293 (experiment 2); and ND5883 and Bowman (experiment $3)$.

Statistical analysis. The mean value for each variable was estimated using data from the three replicate leaf segments for each genotype. A binomial distribution was assumed for all variables (except \%EHRi) and logit link function was used. This was done by fitting a generalized linear model using analysis of deviance. Normality was assumed and tested for \%EHRi and a general linear model was fit using analysis of variance. The experimental effect was included in both models and adjusted means were obtained using NDB112 as reference material. Genotypes were considered as fixed effects. The GLIMMIX procedure implemented in SAS statistical software (version 9.2; SAS Institute Inc., Cary, NC) was used. Mean comparisons were done by Tukey-Kramer multiple range test $(\alpha=0.05)$ when appropriate.

Association between genotype and variable mean value per genotype was examined by principal component analysis (PCA) using software $\mathrm{R}$ (version 2.2.1; R Foundation for Statistical Computing, Vienna). Analysis was based on the correlation matrix of standardized, centered data and was represented graphi- cally using a biplot display (10) constructed with the first two principal components. Lines in the biplot represent vectors corresponding to each variable as they are projected onto the plane defined by two principal components. Long vectors indicate variables that are close to the plane being displayed and are well represented. Small angles between vectors indicate high colinearity between variables, while vectors at or near $90^{\circ}$ and $180^{\circ}$ indicate absence of correlation and large negative correlations between the variables, respectively. The midpoint of each label for the 11 barley genotypes represents corresponding genotypic means as they are oriented in the plane.

\section{RESULTS}

Seedling infection responses. Infection response values for macroscopic symptoms present in the 11 barley genotypes at the seedling stage are shown in Table 1. Variation in these values was between 3 and 9 using the scale of Fetch and Steffenson (8). Disease development with IR values 1 to 3 had small necrotic lesions with no or slight marginal chlorotic halos. Medium-sized necrotic lesions with restricted chlorotic margins were characteristic of IR values 4 to 5 . Higher IR values showed progressive increase in necrotic lesion size and extent of diffuse chlorosis. Interaction compatibility was high in ND5883, Perun, CLE253, Calicuchima-sib, and 21IBON\#69; intermediate in TR6, Ingrid, Morex, and Bowman; and low in ND17293 and NDB112.

Histological characterization of interaction microphenotypes. Early defense microphenotypes in epidermal and mesophyll cells of the 11 genotypes 8,24 , and 48 hai are shown in Figure 1. The interaction microphenotypes determined were in agreement with host cell ROS-associated defense responses. The frequencies of CWA in epidermal cell walls, epidermal and mesophyll cell HR, as well as progress of fungal invasion were determined. At 8 hai in all interactions, numerous germinated spores were observed, with only a small percentage forming hyphal appressoria. Also, at this time, brown circular spots were seen on epidermal cell walls in all 11 accessions (Fig. 1A) whereas very few $\mathrm{DAB}^{+}$sites were seen in epidermal cell walls (Fig. 1B). At 24 hai, appressoria were in contact with anticlinal epidermal cell walls and stomata (Fig. 1C, D, and E).

At 24 and 48 hai, accumulation of $\mathrm{H}_{2} \mathrm{O}_{2}$ was evident in CWA (Fig. 1C and G) as well as in epidermal (Fig. 1C) and mesophyll (Fig. 1D) cell walls. In several interaction sites, epidermal and mesophyll cells were completely stained with DAB, indicating HR (Fig. 1F to G, K, and L). HR responses in either prepenetrated (Pre-EHR; Fig. 1F to G) or post-penetrated (Post-EHR; Fig. 1H to I) epidermal cells were occasionally accompanied by more extensive HR in underlying mesophyll cells (Pre-MHR; Fig. 1K to L and Post-MHR; Fig. 1M, respectively). Fungal growth in epidermal cell space was also extensive at 24 and 48 hai. Penetrated epidermal cells did not always show an HR response. Colonization of mesophyll intercellular space, indicative of successful infection, was seen mainly at 48 hai (Fig. $1 \mathrm{~N}$ to $\mathrm{O}$ ). Invasion of mesophyll tissue generally resulted in abundant $\mathrm{H}_{2} \mathrm{O}_{2}$ accumulation. None of the early defense responses in epidermal and mesophyll cells (microphenotypes) were unique to either resistant or susceptible genotypes.

Quantitative analysis of interaction microphenotypes. Differences in microphenotypes at 24 and 48 hai for the 11 genotypes were analyzed by determining the frequency of the six host defense variables and two related to disease progression illustrated in Figure 1. The adjusted estimated means (see Material and Methods) for each variable are shown in Table 2. Genotypes are ordered from most susceptible to most resistant, based on corresponding IR values (Table 1).

Responses at 24 hai. At 24 hai, the most frequently detected host responses were CWA and Pre-EHR followed by Post-EHR. In general, the two defense responses associated with $\mathrm{H}_{2} \mathrm{O}_{2}$ ac- 

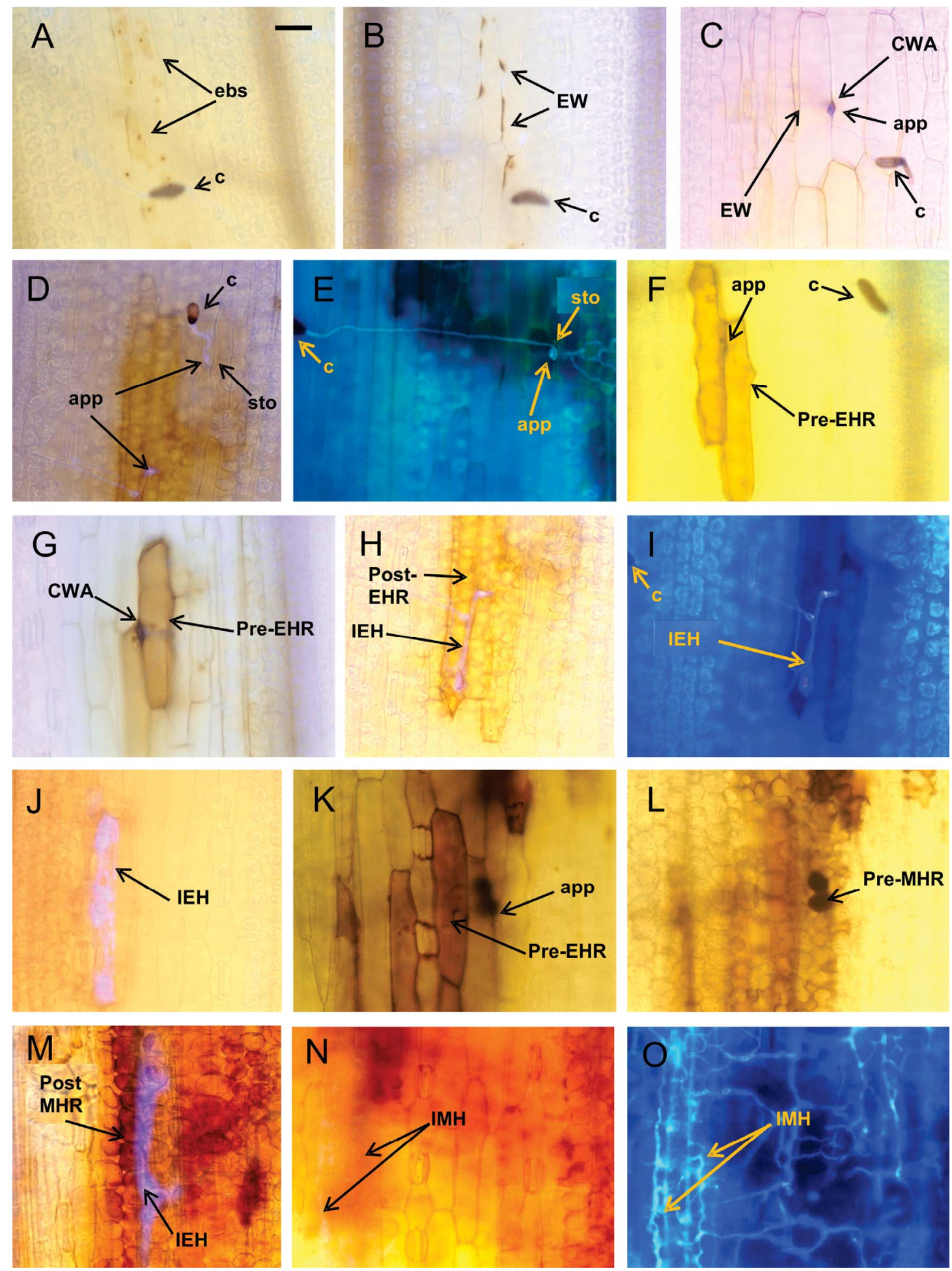

Fig. 1. Interaction microphenotypes induced in Cochliobolus sativus-infected barley leaves 8,24 , and $48 \mathrm{~h}$ after inoculation (hai). Leaf samples were doublestained with 3,3-diaminobenzidine (DAB) and Calcofluor for detection of $\mathrm{H}_{2} \mathrm{O}_{2}$ and fungal structures, respectively. At 8 hai, A, epidermal cell showing brown spots (ebs) in the vicinity of a germinated conidium (c) (out of focus). B, Epidermal cell walls show sites with localized $\mathrm{H}_{2} \mathrm{O}_{2}$ accumulation (EW). At 24 hai, $\mathbf{C}$, DAB-stained cell wall apposition (CWA) (brown structure) is located beneath an appressorium (app); also, a distant site with localized dark browning of epidermal cell walls is indicated. D, One appressorium contacted an anticlinal cell wall of an epidermal cell while another contacted a stoma (sto). E, Hyphae penetrate through a stoma and access the mesophyll. F, Whole DAB-stained epidermal cells indicative of hypersensitive reaction (HR), at prepenetration stages (Pre-EHR) while an appressorium is contacting the anticlinal cell walls of the same cell. G, Epidermal cell expressing Pre-EHR shows a CWA located beneath an appressorium. H, Successful fungal penetration of an epidermal cell seen as intracellular hyphae (IEH) arising from appressorium; the cell is showing postpenetration HR (Post-EHR). I, Epifluorescence image of H facilitates visualization of intracellular hyphae. At 48 hai, J, abundant intracellular hyphae (IEH) in epidermal cell showing Post-EHR. K and L, An appressorium (out of focus) is contacting an epidermal cell in Pre-EHR while underlying mesophyll cells show Pre-MHR; in L, image is focused on the mesophyll layers. M, Intracellular hyphae in epidermal cell (out of focus) and underlying mesophyll in Post-MHR. N, Successful infection as indicated by intercellular hyphae invading the mesophyll (IMH) is accompanied by massive $\mathrm{H}_{2} \mathrm{O}_{2}$ accumulation in this tissue. $\mathbf{O}$, Epifluorescence image of $\mathrm{N}$ showing hyphae branching in the intercellular mesophyll spaces. Microphenotypes described from $\mathrm{C}$ to $\mathrm{M}$ were observed at both 24 and 48 hai in all barley genotypes and corresponded with preinfection defense responses proposed by Ibeagha et al. (20). Microphenotypes described in $\mathrm{N}$ and $\mathrm{O}$ were mainly observed at 48 hai in all genotypes and corresponded with post-infection defense response (20). Differences in percentage of occurrence of each microphenotype were observed among the barley genotypes. Bar $=30 \mu \mathrm{M}$. Figure appears in color online. 
cumulation in mesophyll tissues (Pre-MHR and Post-MHR) were detected at a much lower frequency. These data were consistent with observing extensive IEH and very infrequent IMH at 24 hai. Highest IEH values were observed in susceptible Ingrid and Calicuchima, with resistant NDB112 and ND17293 having much lower frequency of occurrence. Significantly different values for \%EHRi were found comparing those of susceptible CLE253 and Perun (having higher values) and resistant genotypes TR6, ND17293, and NDB112 (IRs 3 to 4). Similarly, Post-EHR values were significantly higher in Ingrid (IR 5) compared with resistant ND17293 and NDB112. Significant differences for CWA were detected between susceptible CLE253 (largest mean) and moderately resistant Morex, TR6, and Ingrid; resistant NDB112; susceptible Calicuchima; and 21IBON\#69. The latter six genotypes showed similarly low frequencies for CWA. There were no significant differences in Pre-EHR, Pre-MHR, and Post-MHR for all genotypes.

Responses at 48 hai. At 48 hai, IEH, IMH, Post-EHR, and Post-MHR were found at much higher frequencies than at 24 hai. In contrast, CWA, Pre-EHR, and Pre-MHR were detected less frequently than at 24 hai. This was consistent with increased epidermal and mesophyll colonization reflected by increased values for IEH and IMH, respectively. In addition, IEH and IMH values were greatest for the most susceptible genotypes and lowest for resistant genotypes. Interestingly, Morex had the largest CWA frequency and NDB112 the lowest. Post-EHR was highest in susceptible CLE253 and lowest in resistant NDB112 and ND17293, moderately resistant Morex and TR6, as well as susceptible Calicuchima and 21IBON\#69.

Responses at 24 and 48 hai. In summary, the lowest levels of fungal invasion, in epidermis (24 and 48 hai) and mesophyll (48 hai) tissues were seen in the most resistant genotypes, including NDB112. In contrast, greater colonization of these tissues was seen for genotypes associated with highly compatible interactions. Importantly, for variables CWA (24 hai) and Post-EHR (48 hai), significantly higher values were obtained with susceptible CLE253, while lower and similar values were found in genotypes exhibiting a wide range of compatibility with the pathogen: (i) resistant NDB112, (ii) moderately resistant Morex and TR6, and (iii) susceptible 21IBON\#69 and Calicuchima. These two variables had intermediate values for the remaining five genotypes. An association between the extent of fungal leaf colonization and of oxidative responses at 24 and 48 hai varied within and among resistant and susceptible genotypes. Susceptible CLE253 (a Perun-derived line from the INIA Uruguay barley breeding program) and susceptible Calicuchima and 21IBON\#69 (both derived from the ICARDA/CIMMYT barley breeding program) were clearly distinct in extent of early oxidative response during fungal colonization.

PCA was done to have a comprehensive view of all data obtained in this study: the 12 defense response variables (CWA, Pre-EHR, Post-EHR, Pre-MHR, Post-MHR, and \%EHRi at 24 and 48 hai), the four fungal infection variables (IEH and IMH at 24 and 48 hai), and 11 barley genotypes. A biplot diagram of this analysis is shown in Figure 2. The first two principal components explained 42 and $21 \%$ of the overall variability, respectively. The longest vectors corresponded to CWA, Pre-EHR, and \%EHRi (24 hai); and Pre- and Post-EHR, Post-MHR, and \%EHRi (48 hai). Thus, these seven variables are most relevant for explaining overall variability among barley genotypes in their response to C. sativus infection. In contrast, the smallest vectors corresponded to Post-MHR, IEH, and IMH at 24 hai and, thus, are not well represented and least informative. Positive and negative highly correlated variables could be identified. Epidermis-related variables CWA (24 hai), Pre and Post-EHR (24 hai), and IEH (48 hai) were positively correlated, having vectors similarly oriented and

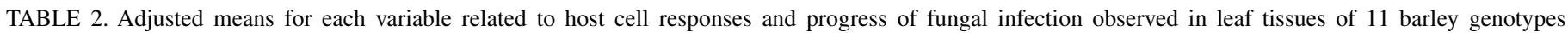
inoculated with Cochliobolus sativus at 24 and 48 h after inoculation (hai) ${ }^{\mathrm{w}}$

\begin{tabular}{|c|c|c|c|c|c|c|c|c|c|c|c|c|c|c|c|c|}
\hline \multirow[b]{2}{*}{ Genotype $^{\mathrm{x}}$} & \multicolumn{2}{|c|}{ CWA } & \multicolumn{2}{|c|}{ Pre-EHR ${ }^{y}$} & \multicolumn{2}{|c|}{ Post-EHR } & \multicolumn{2}{|c|}{ Pre-MHR ${ }^{y}$} & \multicolumn{2}{|c|}{ Post-MHR ${ }^{\mathrm{y}}$} & \multicolumn{2}{|c|}{ IEH } & \multicolumn{2}{|c|}{$\mathrm{IMH}$} & \multicolumn{2}{|c|}{$\% \mathrm{EHRi}^{\mathrm{z}}$} \\
\hline & Mean & SE & Mean & SE & Mean & SE & Mean & SE & Mean & SE & Mean & SE & Mean & SE & Mean & SE \\
\hline \multicolumn{17}{|l|}{24 hai } \\
\hline ND5883 & $0.60 \mathrm{AB}$ & 0.070 & 0.42 & 0.097 & $0.08 \mathrm{AB}$ & 0.034 & $<0.01$ & 0.076 & $<0.01$ & 0.005 & $0.13 \mathrm{AB}$ & 0.027 & $0.13 \mathrm{~A}$ & 0.019 & $79.3 \mathrm{AB}$ & 17.8 \\
\hline Perun & $0.60 \mathrm{AB}$ & 0.071 & 0.41 & 0.095 & $0.34 \mathrm{AB}$ & 0.168 & 0.98 & 5.923 & 0.01 & 0.007 & $0.25 \mathrm{AB}$ & 0.066 & $<0.01 \mathrm{AB}$ & $<0.001$ & $88.7 \mathrm{~A}$ & 17.8 \\
\hline CLE253 & $0.78 \mathrm{~A}$ & 0.058 & 0.41 & 0.095 & $0.17 \mathrm{AB}$ & 0.116 & 0.99 & 2.970 & $<0.01$ & $<0.001$ & $0.14 \mathrm{AB}$ & 0.048 & $<0.01 \mathrm{~B}$ & 0.004 & $91.7 \mathrm{~A}$ & 17.8 \\
\hline Calicuchima & $0.25 \mathrm{~B}$ & 0.058 & 0.21 & 0.072 & $0.09 \mathrm{AB}$ & 0.042 & $<0.01$ & 0.076 & 0.03 & 0.010 & $0.32 \mathrm{~A}$ & 0.059 & $<0.01 \mathrm{AB}$ & $<0.001$ & $38.3 \mathrm{AB}$ & 17.8 \\
\hline 21IBON\#69 & $0.45 \mathrm{~B}$ & 0.071 & 0.29 & 0.084 & $0.03 \mathrm{AB}$ & 0.039 & 0.99 & 3.965 & 0.01 & 0.007 & $0.07 \mathrm{AB}$ & 0.033 & $<0.01 \mathrm{AB}$ & $<0.001$ & $33.3 \mathrm{AB}$ & 17.8 \\
\hline Ingrid & $0.38 \mathrm{~B}$ & 0.069 & 0.42 & 0.096 & $0.19 \mathrm{~A}$ & 0.074 & $<0.01$ & 0.057 & 0.01 & 0.007 & $0.32 \mathrm{~A}$ & 0.058 & $0.05 \mathrm{AB}$ & 0.012 & $80.0 \mathrm{AB}$ & 17.8 \\
\hline Morex & $0.36 \mathrm{~B}$ & 0.067 & 0.23 & 0.076 & $0.09 \mathrm{AB}$ & 0.077 & 0.99 & 2.970 & $<0.01$ & $<0.001$ & $0.17 \mathrm{AB}$ & 0.054 & $<0.01 \mathrm{AB}$ & $<0.001$ & $29.0 \mathrm{AB}$ & 17.8 \\
\hline Bowman & $0.54 \mathrm{AB}$ & 0.072 & 0.31 & 0.088 & $0.06 \mathrm{AB}$ & 0.026 & $<0.01$ & $<0.001$ & $<0.01$ & $<0.001$ & $0.13 \mathrm{AB}$ & 0.026 & $0.07 \mathrm{AB}$ & 0.014 & $63.0 \mathrm{AB}$ & 17.8 \\
\hline TR6 & $0.35 \mathrm{~B}$ & 0.066 & 0.30 & 0.086 & $<0.01 \mathrm{AB}$ & $<0.001$ & 0.99 & 3.965 & $<0.01$ & $<0.001$ & $0.02 \mathrm{AB}$ & 0.016 & $<0.01 \mathrm{AB}$ & $<0.001$ & $<5.0 \mathrm{~B}$ & 17.8 \\
\hline ND17293 & $0.41 \mathrm{AB}$ & 0.070 & 0.30 & 0.085 & 0.03 B & 0.019 & $<0.01$ & 0.057 & 0.01 & 0.007 & 0.14 B & 0.036 & $0.01 \mathrm{~A}$ & 0.006 & $33.3 \mathrm{AB}$ & 17.8 \\
\hline NDB112 & $0.46 \mathrm{~B}$ & 0.032 & 0.29 & 0.038 & $0.03 \mathrm{~B}$ & 0.012 & $<0.01$ & 0.019 & $<0.01$ & 0.002 & $0.09 \mathrm{~B}$ & 0.013 & $<0.01 \mathrm{AB}$ & $<0.001$ & $47.0 \mathrm{AB}$ & 10.3 \\
\hline \multicolumn{17}{|l|}{48 hai } \\
\hline ND5883 & $0.14 \mathrm{AB}$ & 0.048 & 0.15 & 0.056 & $0.38 \mathrm{ABC}$ & 0.070 & 0.03 & 0.031 & $0.18 \mathrm{AB}$ & 0.081 & $0.49 \mathrm{AB}$ & 0.083 & $0.37 \mathrm{~A}$ & 0.093 & $80.7 \mathrm{ABC}$ & 9.2 \\
\hline Perun & $0.27 \mathrm{AB}$ & 0.066 & 0.31 & 0.092 & $0.70 \mathrm{AB}$ & 0.077 & 0.04 & 0.024 & $0.09 \mathrm{~B}$ & 0.041 & $0.75 \mathrm{~A}$ & 0.065 & $0.27 \mathrm{AB}$ & 0.104 & $95.5 \mathrm{~A}$ & 9.2 \\
\hline CLE253 & $0.01 \mathrm{AB}$ & 0.009 & 0.12 & 0.058 & $0.75 \mathrm{~A}$ & 0.068 & 0.01 & 0.007 & $0.39 \mathrm{~A}$ & 0.095 & $0.75 \mathrm{~A}$ & 0.065 & $0.35 \mathrm{AB}$ & 0.115 & 81.0 ABC & 9.2 \\
\hline Calicuchima & $0.07 \mathrm{AB}$ & 0.026 & 0.08 & 0.042 & $0.18 \mathrm{C}$ & 0.045 & 0.01 & 0.015 & $0.14 \mathrm{AB}$ & 0.053 & $0.55 \mathrm{AB}$ & 0.080 & $0.27 \mathrm{AB}$ & 0.079 & $32.7 \mathrm{C}$ & 9.2 \\
\hline 21IBON\#69 & $0.12 \mathrm{AB}$ & 0.041 & 0.35 & 0.096 & $0.35 \mathrm{C}$ & 0.096 & 0.05 & 0.028 & $0.05 \mathrm{~B}$ & 0.027 & $0.57 \mathrm{AB}$ & 0.088 & $0.37 \mathrm{AB}$ & 0.117 & $53.0 \mathrm{BC}$ & 9.2 \\
\hline Ingrid & $0.06 \mathrm{AB}$ & 0.025 & 0.12 & 0.051 & $0.24 \mathrm{C}$ & 0.055 & $<0.01$ & $<0.001$ & $0.17 \mathrm{AB}$ & 0.061 & $0.54 \mathrm{AB}$ & 0.080 & $0.34 \mathrm{~A}$ & 0.089 & 47.7 $\mathrm{ABC}$ & 9.2 \\
\hline Morex & $0.30 \mathrm{~A}$ & 0.070 & 0.40 & 0.100 & $0.37 \mathrm{C}$ & 0.097 & 0.07 & 0.033 & $0.02 \mathrm{~B}$ & 0.014 & $0.51 \mathrm{AB}$ & 0.093 & $0.07 \mathrm{AB}$ & 0.049 & $68.3 \mathrm{ABC}$ & 9.2 \\
\hline Bowman & $0.16 \mathrm{AB}$ & 0.051 & 0.22 & 0.072 & $0.26 \mathrm{BC}$ & 0.058 & 0.04 & 0.040 & $0.21 \mathrm{AB}$ & 0.088 & $0.29 \mathrm{~B}$ & 0.065 & $0.14 \mathrm{AB}$ & 0.052 & $83.3 \mathrm{AB}$ & 9.2 \\
\hline TR6 & $0.12 \mathrm{AB}$ & 0.041 & 0.29 & 0.089 & $0.23 \mathrm{C}$ & 0.086 & 0.06 & 0.029 & $0.03 \mathrm{~B}$ & 0.021 & $0.40 \mathrm{~B}$ & 0.097 & $0.16 \mathrm{AB}$ & 0.079 & $55.0 \mathrm{BC}$ & 9.2 \\
\hline ND17293 & $0.10 \mathrm{AB}$ & 0.032 & 0.21 & 0.072 & $0.15 \mathrm{C}$ & 0.039 & 0.06 & 0.038 & $0.14 \mathrm{AB}$ & 0.054 & $0.42 \mathrm{AB}$ & 0.077 & $0.15 \mathrm{AB}$ & 0.055 & $36.0 \mathrm{BC}$ & 9.2 \\
\hline NDB112 & $0.10 \mathrm{~B}$ & 0.016 & 0.15 & 0.027 & $0.18 \mathrm{C}$ & 0.026 & 0.03 & 0.011 & $0.09 \mathrm{~B}$ & 0.020 & $0.37 \mathrm{~B}$ & 0.037 & $0.08 \mathrm{~B}$ & 0.019 & $52.7 \mathrm{BC}$ & 4.1 \\
\hline
\end{tabular}

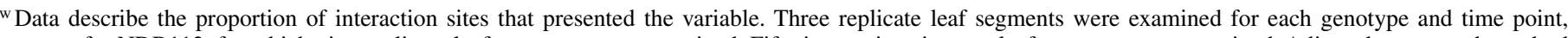
except for NDB112, for which nine replicate leaf segments were examined. Fifty interaction sites per leaf segment were examined. Adjusted means and standard error of the mean (SE) were calculated. Different letters in the same column indicate that means were significantly different based on Tukey-Kramer multiple range test $(P<0.05)$. CWA $=$ cell wall apposition; EHR $=$ epidermal cells showing hypersensitive response $($ HR $)$ at either pre- or post-penetration stages $($ Pre- or Post-, respectively) of fungal infection; MHR = mesophyll cells showing HR, located underneath epidermal cells which were undergoing either pre- or postpenetration stages of fungal infection; IEH = intracellular epidermal hyphae; and IMH = intercellular hyphae in mesophyll tissues.

${ }^{x}$ Genotypes were ordered from least to most resistant according to infection responses scores described in Table 1.

${ }^{y}$ For this variable, genotypic means are not significantly different $(P>0.05)$.

${ }^{z}$ Percentage of penetrated epidermal cells showing HR.
} 
separated by small angles. Two other positively correlated groups of variables were epidermis-related variables CWA and Pre-EHR (48 hai) and mesophyll-related variables Post-MHR (48 hai), IMH (24 hai), and IMH (48 hai). Negative correlations were found between Pre-MHR (24 hai) and Post-MHR (24 hai) and between Pre-MHR (48 hai) and Post-MHR (48 hai), in having vectors oriented in opposite directions.

The most resistant genotypes (NDB112 and ND17293) clustered tightly to the center-right of the plot while genotypes expressing moderate resistance (Bowman, Morex, TR6, and Ingrid) were scattered along the vertical axis. Susceptible genotypes CLE253 and ND5883 clustered to the center-left of the plot while Calicuchima-sib, 21IBON\#69, and Perun were widely dispersed. Susceptible genotypes ND5883, CLE253, and Perun tended to have higher levels of oxidative responses at 24 hai in epidermal cells (CWA, Pre-EHR, and Post-EHR) and for variables describing fungal invasion progress in epidermis and mesophyll tissues at 48 hai (IEH and IMH). In contrast, resistant NDB112 and ND17293 showed lower levels for these same variables. Interestingly, the weak association observed between moderately resistant Morex and TR6 and other resistant geno- types (NDB112 and ND17293) could be explained by a higher frequency of late (48 hai) oxidative responses, including CWA, EHR, and MHR, associated with prepenetrated epidermal tissues observed in Morex and TR6.

\section{DISCUSSION}

We wished to investigate whether different barley genotypes with diverse resistance and susceptibility traits might respond with correspondingly diverse cellular defense responses when inoculated with an isolate of $C$. sativus. This was done by analysis of $\mathrm{H}_{2} \mathrm{O}_{2}$ accumulation in host cells as well as progress of fungal invasion of $C$. sativus-inoculated leaves of 11 barley genotypes exhibiting different levels of SB resistance (8, 24, and 48 hai).

The $C$. sativus isolate used (i.e., 04.1.4) exhibited low, intermediate, or high virulence on different barley genotypes based on a macroscopic symptom (IR-based) scoring method (see Materials and Methods and Table 1). High virulence observed on ND5883 and low virulence on NDB112 and Bowman barley genotypes indicated that isolate 04.1 .4 is pathotype 1 . These three barley genotypes can be used to distinguish $C$. sativus pathotypes

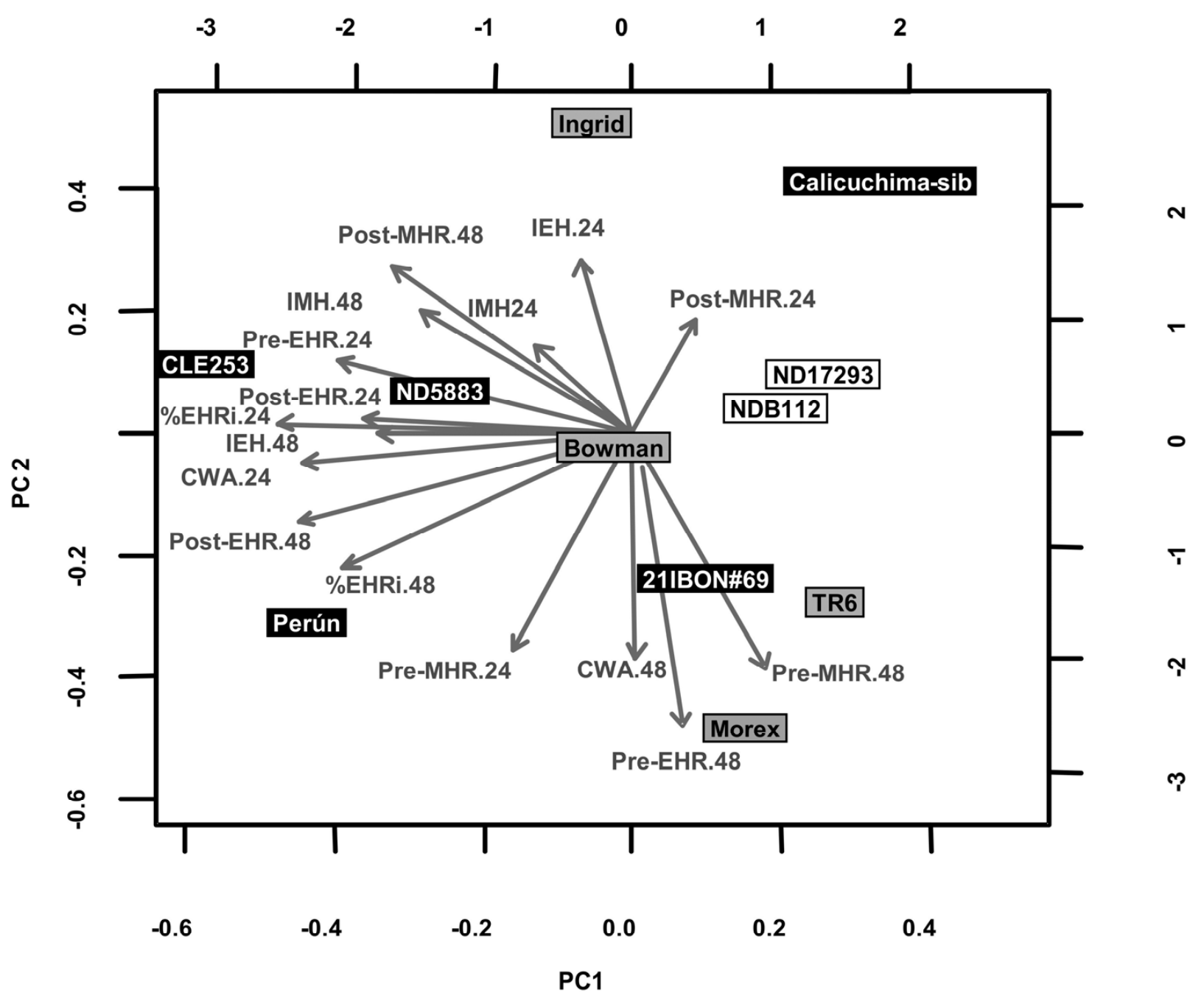

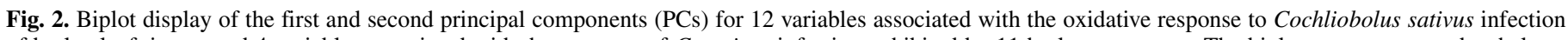

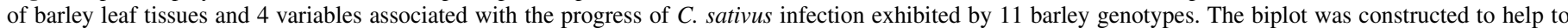

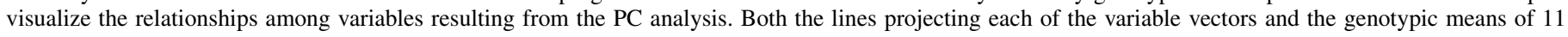

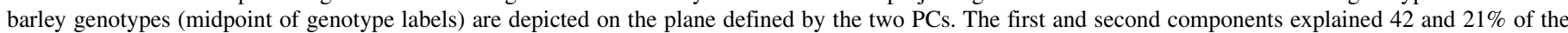

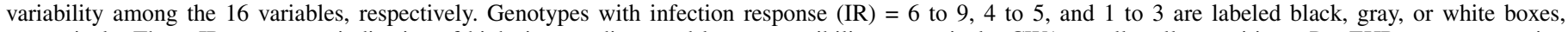

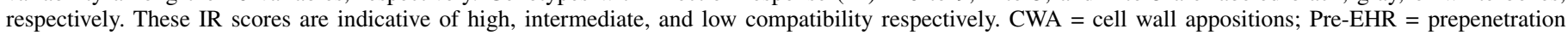

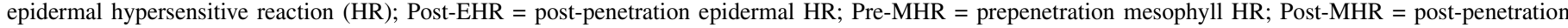

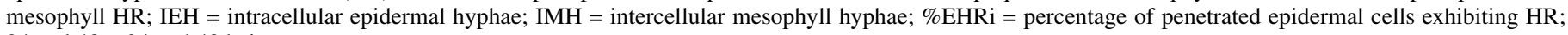
24 and $48=24$ and 48 hai. 
0,1 , and 2 (43). High virulence on Calicuchima-sib is also consistent with this assignment; this cultivar is sensitive to pathotype 1 and resistant to pathotype 2 (5).

We found that most of the genotypes having similar IR scores were genetically unrelated, suggesting that the genetic origins of their defense response mechanisms may be different. Genotype NDB112, however, is considered to be the direct donor of durable SB resistance present in Morex (39), and has also been regarded as related to Bowman resistance. The IR scores for these three genotypes were only moderately similar (IR 3 to 5), indicating that resistant traits and defense responses are likely to be distinct. Very similar susceptibility traits could be expected for Perun and CLE253, a Perun-derived line. Taken together, results indicate that both resistant and susceptible macrophenotypic traits in the different cultivars likely involve distinct mechanisms.

We found the same epidermal host cell responses (CWA and Pre- and Post-EHR) against $C$. sativus reported by Schäfer et al. (36) as part of a preinfection defense expressed by Haisa barley and its mutant albostrians. In addition, our study included analysis of mesophyll cell responses (Pre- and Post-MHR). Our results were different in that we found that CWA and Pre- and Post-HR in epidermal cells were not effective barriers because they were also found in susceptible genotypes (36). Notably, significantly larger frequencies of CWA (at 24 hai) as well as Post-EHR and Post-MHR (at 48 hai) were exhibited by susceptible genotype CLE 253 compared with resistant NDB112. The highest values for \%EHRi were also associated with susceptible genotypes at both 24 and 48 hai. Therefore, our data suggest a need for caution when interpreting how these early cellular responses are correlated with effectiveness in preventing successful pathogen infection.

CWA as a defense mechanism has been studied extensively in interactions involving biotrophic, hemibiotrophic, and necrotrophic fungi $(6,19-22)$. CWA has been suggested to act as a physical barrier to impair fungal penetration, and also to contain cells exhibiting HR. The barrier generated results in blocked plasmodesmata and may prevent spread of cell death signals in neighboring symplast (3). Localized $\mathrm{H}_{2} \mathrm{O}_{2}$ accumulation in CWA, as detected by DAB staining, is associated with effective CWA in the barley-powdery mildew interaction (19). We found a significantly lower occurrence of $\mathrm{DAB}^{+} \mathrm{CWA}$ at 24 hai concurrent with extensive fungal colonization of epidermal cells by susceptible Calicuchima-sib, suggesting a role for CWA in defense. Intriguingly, susceptible CLE253 had the highest CWA occurrence at 24 hai and highest levels of intracellular hyphae in the epidermis at 48 hai. Additional study of this result is needed to better understand why the CLE253 CWA response was either largely ineffective as a barrier or whether some other role for this response is indicated. We also found a substantial decrease in appearance of CWA at 48 hai compared with that at 24 hai for all genotypes. Thus, our results were in contrast with those of Ibeagha et al. (20) for the wheat-C. sativus interaction in two respects. Although based on a small number of genotypes, they reported a threefold higher percent CWA in resistant compared with susceptible genotypes. Also, they found CWA occurrence to be greater 40 hai compared with 20 hai. Overall, our results indicate that CWA may play a role in earlier stages of $C$. sativus infection on barley. CWA appears to impair fungal penetration but it might not provide a fully effective barrier. Detailed structural and chemical characterization of CWAs generated during infection on a given host may help resolve what roles these formations play during pathogen interaction.

Failure to form effective CWA appears to trigger HR as a second line of defense to effectively contain biotrophic Blumeria graminis f. sp. hordei on barley $(36,41,44)$. In addition, both CWA and HR in penetrated epidermal cells were observed in interaction of Ingrid barley (Mlo) or 'BCIngrid' mlo-5 with hemibiotrophic Magnaporthe grisea; however, the outcomes from these interactions were resistance and susceptibility, respectively. $M$. grisea-induced HR on BCIngrid mlo-5 may not be triggered soon enough to prevent disease, may result from cell disruption, and may be associated with susceptibility (21). The inhibition of biotrophic Puccinia striiformis f. sp. tritici hyphal growth was not associated with extensive plant cell death and $\mathrm{H}_{2} \mathrm{O}_{2}$ accumulation in 'Guardian', a wheat genotype expressing partial, adult plant resistance to yellow rust (28). Moreover, HR has been shown to facilitate plant infection by the necrotrophic fungi Botrytis cinerea (14).

In this study, HR responses were detected in epidermal and mesophyll cells associated with either prepenetration or postpenetration stages of fungal infection of epidermis tissue. HR responses were also detected in resistant and susceptible genotypes but at different frequencies. Differences in Pre-EHR and Pre-MHR (at 24 and 48 hai) were not statistically different comparing means for each genotype (Table 2). This suggests that these prepenetration defense mechanisms are likely to be basal responses shared by resistant and susceptible genotypes. Thus, variables such as these, considered independently, are unlikely to be informative for understanding differences that distinguish susceptibility and resistance. In contrast, significantly different means were found for HR in epidermis and mesophyll cells in resistant and susceptible genotypes associated with penetrated epidermal cells (Post-EHR at 24 and 48 hai and Post-MHR at 48 hai). Higher post-penetration HR frequencies were associated with some susceptible genotypes, and these responses may, in fact, indicate loss of control of oxidative response reactions in a penetrated cell. For susceptible Calicuchima-sib, however, abundance of intracellular hyphae in epidermal tissues was not accompanied by a large post-penetration EHR.

A significantly reduced HR response in pre- and post-penetrated epidermal cells was also found in resistant versus susceptible wheat genotypes infected with $C$. sativus. The differences in HR frequency between resistant and susceptible genotypes, however, were not evident until 60 hai (20). Our results suggest that epidermal HR at post-penetration stages (Post-EHR) may represent a host susceptibility mechanism rather than an effective defense. This idea is in contrast with conclusions of Schaffer et al. (36) using barley but in agreement with those of Ibeagha et al. (20) using wheat.

Responses of susceptible CLE253 versus Calicuchima and 21IBON\#69 sharply contrasted, in that significantly higher frequencies for CWA (24 hai) and Post-EHR (48 hai) were found in susceptible CLE253 compared with susceptible Calicuchima and 21IBON\#69. The much lower oxidative responses and abundant fungal growth in Calicuchima and 21IBON\#69 illustrated a wide variation in barley susceptibility to $C$. sativis infection. Unlike susceptible genotypes, resistant and moderately resistant genotypes did not differ significantly in response to $C$. sativus infection. An exception was CWA at 48 hai, in which response in Morex was higher than in NDB112. Common patterns in defense responses appear to be shared in resistant NDB112 and ND17293 and in moderately resistant TR6 and Morex. Whether the mechanisms underlying these defense responses are genetically related must await further study.

Microscopic analysis of early oxidative responses and progress of fungal infection provided a global overview of resistance and susceptibility in different genotypes $(17,20,28,36)$. The large amount of data generated from analysis of numerous response variables in different host genotypes is difficult to interpret and conceptualize. Multivariate graphical methods are particularly useful in analyzing large complex datasets (10). A PCA biplot was produced using 12 host cell response-associated variables and 4 variables associated with fungal infection progress. This allows for visualization of relationships between barley genotypes and, indeed, we found a large variation between susceptible genotypes. The biplot was also informative for detecting the most relevant 
parameters distinguishing genotypes as well as how parameters and genotypes were related to one another. Notably, the biplot clearly shows higher occurrence of early oxidative responses (24 hai) and greater fungal infection (48 hai) in CLE253, ND5883, and Perun compared with susceptible Calicuchima-sib and 21IBON\#69. The most resistant genotypes (NDB112 and ND17293) showed lower occurrence of oxidative responses. Expression profiling of genes encoding for oxidative stress response enzymes and antioxidant systems could provide useful additional information. Onset of compatible interactions in barley infected with either hemibiotrophic Rhynchosporium secalis or necrotrophic Pyrenophora teres was accompanied by high levels of ROS accumulation (1).

Shetty et al. (38) found that wheat infected with hemibiotroph Septoria tritici resulted in massive $\mathrm{H}_{2} \mathrm{O}_{2}$ accumulation during the necrotrophic phase. They found that $\mathrm{H}_{2} \mathrm{O}_{2}$ did not facilitate fungal growth, in that $\mathrm{H}_{2} \mathrm{O}_{2}$ scavenging with catalase resulted in an increased pathogen growth and decrease of latent period. $\mathrm{H}_{2} \mathrm{O}_{2}$ infiltration in this system had the opposite effect. A role for fungal toxins in loss of control of oxidative processes in mesophyll resulting from excessive $\mathrm{H}_{2} \mathrm{O}_{2}$ accumulation was proposed by Kumar et al. (22). Whether fungal toxins play a role in susceptibility to $C$. sativus in Calicuchima and 21IBON\#69, for example, will be interesting to study. The role of fungal toxins in modulating host cell response can be investigated by comparative analyses of complete fungal genome sequences, targeted gene disruption experiments of candidate genes, and knowledge of corresponding biosynthetic pathways of candidate metabolites (16).

Interestingly, an association between virulence and oxidation stress tolerance has been found for many fungal phytopathogens. The NPS6 gene in C. heterostrophus is required for virulence in maize (24). NPS6 is a nonribosomal peptide synthase involved in siderophore biosynthesis and oxidative stress tolerance $(24,31)$. Deletion of NPS6 orthologs in several fungal phytopathogens, including C. miyabeanus, Fusarium graminearum, and Alternaria brassisicola, resulted in similar phenotypes, suggesting a highly conserved function for this gene. During fungal infection, extracellular siderophores may not act as phytotoxins but, instead, supply nutritional iron to the pathogen for their survival in hosts (31). NPS6-dependent iron sequestration may also be directly involved in pathogen tolerance to oxidative stress (46). An NPS6deletion mutant of C. sativus (isolate ND90Pr, pathotype 2), however, showed only slightly reduced virulence on Bowman barley compared with the wild type. This indicates that, although NPS6 is involved in C. sativus virulence, it is not the major virulence factor in this isolate (25). Leng and Zhong (25) suggested that virulence factors in this $C$. sativus isolate may be related to still-unknown polyketides or nonribosomal peptides. Deletion mutants in pptl, impaired in $4^{\prime}$-phosphopantetheinylation of conserved serine residues required for activating either polyketides synthases or nonribosomal peptide synthases, had marked decreased virulence and other pleiotropic effects, including inability to produce siderophores, tolerate $\mathrm{H}_{2} \mathrm{O}_{2}$ oxidative stress during growth, produce melanin, and synthesize lysine.

The same range of host defense responses was present in both susceptible and resistant barley genotypes inoculated with $C$. sativus in our study. Why some genotypes are more efficient than others in defense is not clear. It may be that different reactions observed along a single leaf might result from local variation in the pattern of signal release at each interaction site as well as spatial and temporal differences in the expression of defenserelated genes at the cellular level. These sources of variation may explain why pathogen invasion succeeds at some interaction sites whereas, in others, fungal growth can be limited by a rapid and efficient response by a single cell or cluster of host cells under attack. Different gene expression patterns were observed only when comparing individual resistant and infected cells in the
barley-B. graminis f. sp. graminis interaction. In this interaction, similar, early localized cell responses such as papilla deposition and cell wall reinforcement were evident in both susceptible and resistant epidermal cells after attack (13). Interestingly, Ingrid barley showed similar patterns of overrepresented and underrepresented functional categories of genes as part of the transcriptional response to nonadapted (nonhost) and adapted (host) isolates of three fungal pathogens. This suggests that both nonhost resistance and basal host defense are functionally related. The authors also noted that basal host defense involved more complex regulation than did nonhost resistance (45). Results presented in our study also suggest that differences in host cell responses exhibited by resistant and susceptible barley genotypes would seem to be more quantitative rather than qualitative.

We conducted a comprehensive analysis to characterize and compare the barley-C. sativus interaction microphenotypes exhibited by diverse resistant and susceptible barley genotypes. Our results suggest that oxidative responses in epidermis and mesophyll tissues at post-penetration stages and progress of pathogen colonization in the first 48 hai are informative parameters for characterization of diverse resistance and susceptibility traits for this disease. Accordingly, this information could be useful in further characterizing putatively diverse, novel SB resistance. Moreover, evidence for contrasting host cell response patterns in different susceptible and resistant genotypes is provided. This study serves to broaden and enhance our understanding of the molecular cellular basis of barley-C. sativus interactions.

\section{ACKNOWLEDGMENTS}

This research was supported by a competitive grant awarded by the Instituto Nacional de Investigación Agropecuaria, Uruguay (FPTA 219). Barley seeds were kindly provided as follows: K. H. Kogel (Ingrid); B. J. Steffenson (NDB112, Mores, and ND5883); P. M. Hayes (Calicuchimasib); and S. Pereyra (all others). S. Pereyra, A. Castro, and S. German's critical comments along the research process are deeply appreciated. We also thank M. Vaio and P. R. Gill for critical reading of the manuscript.

\section{LITERATURE CITED}

1. Able, A. 2003. Role of reactive oxygen species in the response of barley to necrotrophic pathogens. Protoplasma 221:137-143.

2. Albín, J. 2008. Caracterización genética y sanitaria de una colección de germoplasma de cebada por resistencia a mancha borrosa. Tesis Ing. Agr. Montevideo, Uruguay. Facultad de Agronomía. UdelaR. http:// 164.73.52.13/iah/textostesis/2008/3491alb2.pdf

3. An, Q., Ehlers, K., Kogel, K.-H., van Bel, A. J. E., and Hückelhoven, R. 2006. Multivesicular compartment proliferate in susceptible and resistant MLA12-barley leaves in response to infection by the biotrophic powdery mildew fungus. New Phytol. 172:563-576.

4. Arabi, M. I. E., Al-Daoude, A., Shoaib, A., and Jawhar, M. 2011. Transcriptional interactions during barley susceptible genotype infection with Cochliobolus sativus. Russ. J. Genet. 47:879-883.

5. Bilgic, H., Steffenson, B. J., and Hayes, P. M. 2006. Molecular mapping of loci conferring resistance to different pathotypes of the spot blotch pathogen in barley. Phytopathology 96:699-705.

6. Fernández-Aparicio, M., Prats, E., Emeran, A. A., and Rubiales, D. 2009. Characterization of resistance mechanisms to powdery mildew (Erysiphe betae) in beet (Beta vulgaris). Phytopathology 99:385-389.

7. Fetch, T. G., Jr., and Steffenson B. J. 1994. Identification of Cochliobolus sativus isolates expressing differential virulence on two-row barley genotypes from North Dakota. Can. J. Plant Pathol. 16:202-206.

8. Fetch, T. G., Jr., and Steffenson, B. J. 1999. Rating scales for assessing infection responses of barley infected with Cochliobolus sativus. Plant Dis. 83:213-217.

9. Fetch, T. G., Jr., Steffenson, B. J., Bockelman, H. E., and Wesenberg, D. M. 2008. Spring barley accessions with dual spot blotch and net blotch resistance. Can. J. Plant Pathol. 30:534-542.

10. Gabriel, K. R. 1971. The biplot graphic display of matrices with applications to principal component analyses. Biometrica 58:453-467.

11. Gaudet, D. A., Wang, Y., Penniket, C., Lu, Z. X., Bakkeren, G., and Laroche, A. 2010. Morphological and molecular analysis of host and nonhost interactions involving barley and wheat and the covered smut pathogen Ustilago hordei. Mol. Plant-Microbe Interact. 23:1619-1634. 
12. Ghazvini, H., and Tekauz, A. 2008. Host-pathogen interactions among barley genotypes and Bipolaris sorokiniana isolates. Plant Dis. 92:225233.

13. Gjetting, T., Carver, T. L. W., Skøt, L., and Lyngkjær, M. F. 2004. Differential gene expression in individual papilla-resistant and powdery mildew-infected barley epidermal cells. Mol. Plant-Microbe Interact. 17:729-738.

14. Govrin, E. M., and Levine, A. 2000. The hypersensitive response facilitates plant infection by the necrotrophic pathogen Botrytis cinerea. Curr. Biol. 10:751-757.

15. Gyawali, S. 2010. Association mapping of resistance to common root rot and spot blotch in barley, and population genetics of Cochliobolus sativus. Ph.D. thesis, North Dakota State University, Fargo.

16. Howlett, B. J. 2006. Secondary metabolite toxins and nutrition of plant pathogenic fungi. Curr. Opin. Plant Biol. 9:371-375

17. Hückelhoven, R. 2007. Cell wall-associated mechanisms of disease resistance and susceptibility. Annu. Rev. Phytopathol. 45:101-127.

18. Hückelhoven, R., Dechert, C., Trujillo, M., and Kogel, K.-H. 2001. Differential expression of putative cell death regulator genes in nearisogenic, resistant and susceptible barley lines during interaction with powdery mildew fungus. Plant Mol. Biol. 47:739-748.

19. Hückelhoven, R., Fodor, J., Preis, C., and Kogel, K.-H. 1999. Hypersensitive cell death and papilla formation in barley attacked by the powdery mildew fungus are associated with hydrogen peroxide but not with salicylic acid accumulation. Plant Physiol. 119:1251-1260.

20. Ibeagha, A. E., Hückelhoven, R., Schäfer, P., Singh, D. P., and Kogel, K.-H. 2005. Model wheat genotypes as tools to uncover effective defense mechanisms against the hemibiotrophic fungus Bipolaris sorokiniana. Phytopathology 95:528-532.

21. Jarosch, B., Kogel, K.-H., and Schaffrath, U. 1999. The ambivalence of the barley Mlo locus: mutations conferring resistance against powdery mildew (Blumeria graminis f. sp. hordei) enhance susceptibility to the rice blast fungus Magnaporthe grisea. Mol. Plant-Microbe Interact. 12:508-514.

22. Kumar, J., Hückelhoven, R., Beckhove, U., Nagarajan, S., and Kogel, K.-H. 2001. A compromised Mlo pathway affects the response of barley to the necrotrophic fungus Bipolaris sorokiniana (teleomorph: Cochliobolus sativus). Phytopathology 91:127-133.

23. Kumar, J., Schäfer P., Hückelhoven R., Langen G., Baltruschanr H., Stein E., Nagarajan S., and Kogel K. 2002. Bipolaris sorokiniana, a cereal pathogen of a global concern: cytological and molecular approaches towards better control. Mol. Plant Pathol. 3:185-195.

24. Lee, B. N., Kroken, S., Chou, D. Y. T., Robbertse, B., and Yoder, O. C. 2005. Functional analysis of all nonribosomal peptide synthases in Cochliobolus heterostrophus reveals a factor, NPS6, involved in virulence and resistance to oxidative stress. Eukaryot. Cell 4:545-555.

25. Leng, Y., and Zhong, S. 2012. Sfp-type $4^{\prime}$-phsphopantetheinyl transferase is required for lysine synthesis, tolerance to oxidative stress and virulence in the plant pathogenic fungus Cochliobolus sativus. Mol. Plant Pathol. 13:375-387.

26. Levine, A., Tenhaken, R., Dixon, R., and Lamb, C. $1994 . \mathrm{H}_{2} \mathrm{O}_{2}$ from the oxidative burst orchestrates the plant hypersensitive disease resistance response. Cell 79:583-593.

27. Luna, E., Pastor, V., Robert, J., Flors, V., Mauch-Mani, B., and Ton, J. 2011. Callose deposition. A multifaceted plant defense response. Mol. Plant-Microbe Interact. 24:183-193.

28. Melichar, J. P. E., Berry, S., Newell, C, MacCormack, R., and Boyd, L. A. 2008. QTL identification and microphenotype characterization of the developmentally regulated yellow rust resistance in the UK cultivar Guardian. Theor. Appl. Genet. 117:391-399.

29. Millett, B. P., Xiong, Y., Dahl, S. K., Steffenson, B. J., and Muehlbauer,
G. J. 2009. Wild barley accumulates distinct sets of transcripts in response to pathogens of different trophic lifestyles. Physiol. Mol. Plant Pathol. 74:91-98.

30. Nanda, A. K., Andrio, E., Marino, D., and Dunand, C. 2010. Reactive oxygen species during plant-microorganism early interactions. J. Integr. Plant Biol. 52:195-204.

31. Oide, S., Moeder, W., Krasnoff, S., Gibson, D., Haas, H., Yoshioka, K., and Turgeon, B. G. 2006. NPS6, encoding a nonribosomal peptide synthetase involved in siderophre-mediated iron metabolism, is a conserved virulence determinant of plant pathogenic Ascomycetes. Plant Cell 18: 2836-2853.

32. Pereyra, S., Diaz, M., and Stewart, S. 2005. Manual de identificación de enfermedades en cereales de invierno. Bol. Divulgación 61:50. INIA, Uruguay.

33. Pereyra, S, and Stewart, S. 1996. Screening for disease resistance in Uruguay. Barley Newsl. 40:45-47.

34. Rohringer, R., Kim, W. K., Samborski, D. J., and Howes, N. K. 1977. Calcofluor: an optical brightener for fluorescence microscopy of fungal plant parasites in leaves. Phytopathology 67:808:810.

35. Roy, J. K., Smith, K. P., Muehlbauer, G. J., Chao, S., Close, T. J., and Steffenson, B. J. 2010. Association mapping of spot blotch resistance in wild barley. Mol. Breed. 26:243:256.

36. Schäfer, P., Hückelhoven, R., and Kogel, K.-H. 2004. The white barley mutant albostrians shows a supersusceptible but symptomless interaction phenotype with the hemibiotrophic fungus Bipolaris sorokiniana. Mol. Plant-Microbe Interact. 17:366-373

37. Shetty, N. P., Jørgensen, H. J. L., Jensen, J. D., Collinge, D. B., and Shetty, H. S. 2008. Roles of reactive oxygen species in interactions between plants and pathogens. Eur. J. Plant Pathol. 121:267-280.

38. Shetty, N. P., Mchrabi, R., Lütken, H., Haldrup, A., Kema, G. H. J., Collinge, D. B., and Jørgensen, H. J. L. 2007. Role of hydrogen peroxide during the interaction between the hemibiotrophic fungal pathogen Septoria tritici in wheat. New Phytol. 174:637-647.

39. Steffenson, B. J., Hayes, P. M., and Kleinhofs, A. 1996. Genetics of seedling and adult plant resistance to net blotch (Pyrenophora teres $\mathrm{f}$. teres) and spot blotch (Cochliobolus sativus) in barley. Theor. Appl. Genet. 92:552-558.

40. Tenhaken, R., Levine, A., Brisson, L. F., Dixon, R. A., and Lamb, C. 1995. Function of the oxidative burst in hypersensitive disease resistance. Proc. Natl. Acad. Sci. USA 92:4158-4163.

41. Thordal-Christensen, H., Zhang, Z., Wei, Y., and Collinge, D. B. 1997. Subcellular localization of $\mathrm{H}_{2} \mathrm{O}_{2}$ in plants. $\mathrm{H}_{2} \mathrm{O}_{2}$ accumulation in papillae and hypersensitive response during the barley-powdery mildew interaction. Plant J. 11:1187-1194.

42. Torres, M. A. Jones, J. D. G., and Dangl, J. L. 2006. Reactive oxygen species signaling in response to pathogens. Plant Physiol. 141:373-378.

43. Valjavec-Gratian, M., and Steffenson, B. J. 1997. Pathotypes of Cochliobolus sativus on barley in North Dakota. Plant Dis. 81:1275-1278.

44. Vanacker, H., Carver, T. L. W., and Foyer, C. H. 2000. Early $\mathrm{H}_{2} \mathrm{O}_{2}$ accumulation in mesophyll cells leads to induction of glutathione during the hyper-sensitive response in the barley-powdery mildew interaction. Plant Physiol. 123:1289-1300.

45. Zellerhoff, N., Himmerbach, A., Dong, W., Bieri, S., Schaffrath, U., and Schweizer, P. 2010. Non-host resistance of barley to different fungal pathogens is associated with largely distinct quantitative transcriptional responses. Plant Physiol. 152:2053-2066.

46. Zhang, N., NurAinIzzati, Z., Scher, K., Condon, B. J., Horwitz, B. A., and Turgeon, G. 2013. Iron, oxidative stress and virulence: roles of the ironsensitive transcription factor Sre1 and the redox sensor ChAp1 in the maize pathogen Cochliobolus heterostrophus. Mol. Plant-Microbe Interact. 26:1473-1485. 